\title{
THE EFFECTIVENESS OF FACEBOOK PROMOTING THE BRANDS OF SLOVAK WELLNESS HOTELS BASED ON THE DEA METHODOLOGY

\author{
Dominika Moravcikova $^{1}$, Anna Krizanova ${ }^{2}$
}

\begin{abstract}
This contribution presents an evaluation of the effectiveness of the Facebook social network promoting the brands of a number of selected Slovak wellness hotels based on the DEA (Data Envelopment Analysis) methodology and its selected models.

The research question is that hotel guests use the funpages of the Slovak wellness hotels on the Facebook social network to learn more about its services and also how the Slovak wellness hotels use their funpages to promote their brand and communicate with their consumers.

During the four months in 2018 (September - December), data on input and output variables was collected, with data from photos, videos and links to "funpage" hotels on Facebook and output to "Likes" and "Comments". The measurement of the efficiency of these input and output variables in order to assess the effectiveness of 16 wellness hotel brands operating in the Slovak Republic was based on an input-oriented CCR DEA model with weight adjustment via the Assurance Region.

The number of Likes and comments on the Facebook pages of the 16 Slovak wellness hotels suggests that hotel guests use Facebook to learn more about the services and events they provide. The DEA model is therefore an effective tool to help evaluate the effectiveness of a business in a hotel sector on a social network, such as Facebook, in promoting its brands, as it uses multiple variables and does not necessarily require an input-output relationship. The results of using this method confirmed the research question.
\end{abstract}

JEL Classification Numbers: C52, C67, M31, M37, DOI: 10.12955/cbup.v7.1365

Keywords: effectiveness, social network Facebook, Data Envelopment Analysis, brand, Slovak hotel industry, wellness hotel

\section{Introduction}

The term social network belongs to the social media category and in today's world social networks have gained a significant position thanks to the many benefits they bring to both consumers and businesses (Faranda \& Roberts, 2019). The term social network was first used in Boyd and Ellison (2007), a scientific publication that defined social media as a type of website for media and social content sharing and thus began to build social networks. A specific feature of social media is that every user can participate in the creation of their content, with content in the form of text, audio, video, or photo (Pham, Shancer, \& Neslon, 2019). Facebook is currently the largest social network, as its users exceeded two billion by 31 December 2017. The use of Facebook is an opportunity to improve the image of the company, building a brand (Kliestikova \& Janoskova, 2017), launch a new product on the market, PR communication tools (Nadanyiova, 2017), targeting specific groups by their interests (Kolarova, Bediova \& Rasticova, 2017) through the chosen communication, it is possible to achieve an increase in the effectiveness of sales growth. Over the last decade, Facebook has attracted not only the attention of individual users (Okuneviciute \& Pranskeviciute, 2018), but business entities too, especially hotels. For the hotel industry, integration with Facebook is essential to support guest conversations, increase pageviews, and generate new traffic (Kang, 2018). A number of Slovak hotels have created so-called funpages with the hope of establishing interaction with other companies for promoting brand sales. According to the Ministry of Transport and Construction of the Slovak Republic (2018), almost 5.4 million domestic and foreign tourists visited the Slovak Republic, which represents an increase of $7 \%$ compared to 2016. It follows that tourism is developing in a good direction, but at the same time it places higher demands on services. The increase in visitors last year also brought an increase in the number of overnight stays in Slovakia. Their number increased by 5.6\% and totaled 14.9 million overnight stays.

As mentioned above, the increase in social networking and enterprise "funpages" is enormous, hence their analysis of effectiveness is necessary, as information distribution is changing (Olah, Zeman, Blogh \& Popp, 2018). In 1995, Coelli (1995) introduced a method of analyzing packaging data, which is a significant means of economic management to measure the efficiency of production units grouped in a given group.

\footnotetext{
${ }^{1}$ University of Zilina, Faculty of Operations and Economics of Transport and Communications, Zilina, Slovakia, dominika.moravcikova@fpedas.uniza.sk

${ }^{2}$ University of Zilina, Faculty of Operations and Economics of Transport and Communications, Zilina, Slovakia, anna.krizanova@fpedas.uniza.sk
} 
For this reason, this contribution will use the DEA (Data Envelopment Analysis) methodology to evaluate the effectiveness of using the Facebook social network to support Slovak hotel brands; which is also the main objective of this contribution.

\section{Literature Review}

The use of Internet information and communication technologies has intensified at a massive pace throughout the world. By June 30, 2018, the number of Internet users worldwide has exceeded 4 billion (55\% of the world's total population). In terms of Internet penetration in the home, the Internet reaches 36.1\% of people in Africa, 49\% in Asia, 85.2\% in Europe, 67.2\%, in Latin America, 95\% in North America and 68.9\% in Australia (Internet World Stats ,2018). As of 31 December 2017, the number of Internet users in the Slovak Republic is 4,629,641, which represents $85 \%$ of Internet penetration in households (Internet World Stats, 2018). In their study, Jakovic and Galetic (2014) state that consumers have a tendency to select and evaluate hotel services in this respect through a set of attributes and values that are clear, trustworthy and meaningful to them (brand).

In her study, Barba-Gutiérrez, Adenso-Díaz \& Lozano (2009) presented the DEA methodology, which is also used in this article, to measure the effectiveness of a particular set of decision-making units (DMU), the so-called DEA. DMU based on input-to-output transformation, with an efficiency score of 0 to 1 for each unit being evaluated. Jablonsky \& Dlouhy (2015) classifies DEA models based on their input orientation (if the efficiency score is one, the unit is effective; in the case of an inefficient unit, the efficiency score is close to zero) or outputs (if the efficiency score is one, the unit it is effective, in the case of an inefficient unit, the efficiency score is greater than one), but also by the nature of the range revenue. It follows that the CCR DEA models are sometimes referred to as CRS models (constant returns to scale) and BCC DEA models (Charnes, Cooper \& Rhodes, 1978). Banker, Charnes \& Cooper (1984) reported that the difference between these models is in the nature of the range yields, i. e. the CCR DEA model assumes constant returnes to scale, and the BCC DEA model, which is essentially a modification thereof, considers a variable scale. In fact, DEA analysis models do not require any data on costs or formal relationships between inputs and outputs. From the point of view of the practical use of CCR and BCC models in the theory of marketing communication, Shuai \& Wu (2011) and Lothia, Donthu \& Yaveroglu (2007), we recommend using only CCR models, as it has been shown that the goals of using basic BCC models are not quite realistic because of the variability scale. As stated by Jablonsky \& Dlouhy (2015), the DEA method is a fundamental tool for evaluating the effectiveness of marketing communication, as it fulfills several important functions that can make the hotel successful on the market by knowing how effective its marketing communication is.

This hotel efficiency analysis is limited to a small number of studies. Among the first work on this issue is Baker \& Riley (1984), who suggested using ratios to measure the effectiveness of accommodation. In further work, the authors considered using cost optimization to analyze the effectiveness of tourist equipment management (Naves \& Lourenco, 2009). As a first work in the DEA model line, 31 private travel resorts were analyzed (Bell \& Morey, 1995). For analysis, the authors used the DEA-CCR model and considered inputs as the current level of travel costs in the area (for hotel operation including marketing activities, car rental), nominal level of other expenditures, environmental status (number of bargaining discounts, percentage of people entering the current cost of labor (technology, salaries, space, etc.). The output was the level of service provided to the customer (exceptional, average). Later Morey \& Dittman (1995) analyzed the effectiveness of 54 US hotels using the DEA CCR models and crosssectional input-output data. The inputs were used for running costs, energy costs, employee salaries, promotion costs, and cash and non-monetary remuneration for administrative staff. The used outputs were hotel revenues, market share, and growth rates. Among other things, Johns, Howcroft \& Drake (1997) analyzed 15 British hotels for 12 months using the DEA-CCR model. For outputs they used the number of overnight stays, processed services and the revenue from restaurant activities. For inputs they used the number of available rooms, hours worked, cost of restaurant activity and other operating costs.

\section{Methodology}

This contribution deals with the evaluation of the effectiveness of using the social network Facebook to promote the brand of the selected 16 Slovak wellness hotels. As shown above, the most commonly used method for assessing effectiveness, in addition to the Economic Value Added (EVA) method (Salaga, Bartosova \& Kicova), is the DEA method that reflects only some of the factors that affect the overall 
effectiveness of a hotel's marketing communication, i. e. the individual funpage of the selected Slovak wellness hotels on Facebook are DMU1, DMU2, ... DMUn, which produce outputs based on inputs. If one input and one output are considered, the effectiveness would be expressed as the output / input ratio. In practice, however, we encounter that the tools of marketing communication, as well as Facebook, are engaged in activities with multiple inputs, and respectively outputs. For this reason we will use a weighting system for such a grouping, where we denote the set of homogeneous units as U1, U2 ..., Un. Each of the units generates $r$ outputs while consuming m inputs. Then we denote $X=\{x i j, i=1,2, \ldots$, $\mathrm{m} ; \mathrm{j}=1,2, \ldots, \mathrm{n}\}$ as a matrix of inputs and $\mathrm{Y}=\{\mathrm{yij}, \mathrm{i}=1,2, \ldots, \mathrm{r} ; \mathrm{j}=1,2, \ldots, \mathrm{n}\}$ as an output matrix. The Uq inputs and outputs contain the q-th row of the $\mathrm{Xq}$ and $\mathrm{Yq}$ matrices. We can generally say how effective this unit is:

$$
U_{q}=\frac{\text { Weighted sum of outputs }}{\text { Weighted sum of inputs }}=\frac{u_{1} y_{1 q}+u_{2} y_{2 q}+\cdots+u_{r} y_{r q}}{v_{1} x_{1 q}+v_{2} x_{2 q}+\cdots+v_{m} x_{m q}}=\frac{\sum_{i=1}^{r} u_{i} y_{i q}}{\sum_{j=1}^{m} v_{i} x_{j q}}
$$

where $v_{j}, j=1,2, \ldots, m$ are the weights of $j$-th input and $u_{i}, i=1,2, \ldots, r$ are the weights of the $i$-th output. Then optimized, resp. the DMOo virtual unit will also have optimized, resp. target vectors of inputs (xo) and outputs (yo).

As a result, using this method, Kliestik (2009) pointed to a source of determining inefficiency while determining how a production unit can become effective by reducing / increasing inputs, respectively outputs. It also states that the number of decision units should be three times greater than the sum of their inputs and outputs. This efficiency assessment is also an important part of financial analyses (Bartosova \& Kral).

\section{CCR DEA model (the Constant Return to Scale - CRS)}

The authors propose the use of an input-oriented CCR DEA model as the goal is to determine how hotel promotion through Facebook's social network has influenced the consumers in choosing a hotel and not the other way around. The CCR DEA model assumes a decision unit in which the optimal combination of input and output variables is independent of the scope of the operation. This means that through this method we measure the effectiveness for each selected hotel in the Slovak Republic. The target function is to maximize the efficiency score for the hotel subject to the restrictions, i. e. no hotel will be more than $100 \%$ efficient, as input and output weights will be non-zero and positive.

$\begin{array}{lll}\text { Maximize } & z=\sum_{k=1}^{r} u_{k} y_{k q}, & \\ \text { under conditions } & \sum_{k=1}^{r} u_{k} y_{k j}-\sum_{i=1}^{m} v_{i} x_{i j} \leq 0, & \mathrm{j}=1,2, \ldots, \mathrm{n}, \\ & \sum_{i=1}^{m} v_{i} x_{i q}=1, & \\ & u_{k} \geq \varepsilon, & \mathrm{i}=1,2, \ldots, \mathrm{r}, \\ & v_{i} \geq \varepsilon, & \mathrm{j}=1,2, \ldots, \mathrm{m} .\end{array}$

Assurance Region

The model eliminates pseudoefficiency by solving the zero-weight problem. There are no lower limitations for these weights and, moreover, they must meet the condition to be positive. For this reason, it is necessary to modify the CCR DEA model to meet these conditions. For AR access, weights are so limited:

$$
\alpha_{i} \leq \frac{v_{i}}{v_{i_{0}}} \leq \beta_{i}, \quad \mathrm{i}=1,2, \ldots, \mathrm{m},
$$

where $\mathrm{i}_{0}$ and $\mathrm{k}_{0}$ are the indices of the selected input and output for comparison with other inputs and outputs; $\alpha_{i}, \beta_{i}$, are the limits for $\mathrm{i}$-th, resp. $\mathrm{k}$-th input measured in relation to $\mathrm{i}_{0}-\mathrm{th}$, respectively $\mathrm{k}_{0}-$ th output. Values $\alpha_{i 0}=\beta_{i 0}=1$. According to the AR approach, the "funpage" on the Facebook social network of this hotel is effective only when its effectiveness is equal to one.

Inputs, outputs and data collection and analysis

As the CCR DEA model focuses on the efficiency of hotel-user management, the inputs refer to the type of information published by hotels on their Facebook pages (total "links", total "photo" and "videos" and the output are "Likes" ( $\Sigma$ number of likes / number of fans and comments from hotel guests or fans ( $\Sigma$ number of comments / fans count).

The choice of input and output variables for the study in question required extra attention as it affects the effectiveness of the "funpage" in question. The increased number of hotel guests is the result of the hotel's attractiveness, but also many other factors (Meila, 2018) that are outside the analyzed area. In 
addition, measuring the effectiveness of hotels that use Facebook to promote a brand can be challenging, as hotels rarely collect performance data on social networks. For this reason, the output variable is measured as the intermediate result of the Facebook page in the hotel. Subsequently, the output variables reflect the number of "Likes" and "Comments" due to the number of fans for the post.

The proposed model was used for the Facebook "funpages" of the 66 hotels in the Slovak Republic, whose financial but also operative data were published in the Trend weekly in the Trend Top in March 2019 and which have "Facebook" funpages. Of the listed hotels, only the wellness category of hotels was selected, as their marketing communication is at an adequate level with respect to the study in question, ie. the model used a sample of 16 wellness hotels in Slovakia.

Researchers collected data for four months in 2018 (September - December), where data from photos, videos, and "funpage" links on Facebook hotels and "Likes" and "Comments" were input. Measurement of the effectiveness of these input and output variables to assess the hotel brand efficiency was based on an input-oriented CCR DEA model with a weighted adjustment through the Assurance Region.

\section{Results}

Given the main objective of the contribution in question, the following table shows the basic characteristics of the analyzed 16 wellness hotels in the Slovak Republic, including a summary of their input and output characteristics obtained from their "funpages" on Facebook, ie. 9,828 photos, 393 videos, 33 links, 97,640 people and 62,483 comments.

\begin{tabular}{|c|c|c|c|c|c|c|}
\hline No & Hotel & "Fotography" & "Video" & "Links" & "Likes" & "Comments" \\
\hline H1 & Village Resort Hanuliak & 532 & 129 & 4 & 2476 & 987 \\
\hline $\mathrm{H} 2$ & Hotel Dixon & 325 & 378 & 2 & 3478 & 2965 \\
\hline $\mathrm{H} 3$ & Hotel Partizán & 534 & 120 & 3 & 4385 & 3178 \\
\hline $\mathrm{H} 4$ & Hotel Thermalpark & 798 & 289 & 0 & 4328 & 2316 \\
\hline H5 & Hotel Thermal & 670 & 310 & 1 & 3289 & 2143 \\
\hline H6 & Hotel Sorea Máj & 412 & 329 & 2 & 4378 & 2156 \\
\hline $\mathrm{H} 7$ & Hotel Rozsutec & 980 & 121 & 3 & 8765 & 5386 \\
\hline $\mathrm{H} 8$ & Hotel Holiday Park Orava & 784 & 98 & 0 & 7612 & 1840 \\
\hline H9 & Hotel Fugerov Dvor & 451 & 76 & 3 & 6430 & 2134 \\
\hline H10 & $\begin{array}{l}\text { Garden Hotel \& Resort } \\
\text { Oravský Háj }\end{array}$ & 745 & 309 & 3 & 7903 & 3459 \\
\hline H11 & Hotel Jullianin Dvor & 523 & 287 & 2 & 4309 & 5321 \\
\hline H12 & Grand Hotel Bellevue & 970 & 169 & 2 & 5931 & 5476 \\
\hline H13 & Grand Hotel Permon & 643 & 379 & 3 & 10239 & 6490 \\
\hline H14 & Hotel Zochova chata & 510 & 321 & 1 & 9065 & 8654 \\
\hline H15 & Hotel Patince & 364 & 247 & 0 & 6321 & 3657 \\
\hline H16 & Hotel \& Spa Resort Kaskady & 587 & 231 & 4 & 8731 & 6321 \\
\hline
\end{tabular}

Based on the input information on the Facebook "funpages" in the analyzed wellness hotels in the Slovak Republic, the CCR DEA model was applied, including the Assurance Region, which allowed the admissible weights of input variables to be limited (4), in which it is necessary to determine the coefficient values. In the study of the literature of the subject matter, the weight limits have been proposed differently. The most common way was to use the same border for all weights of input variables:

$$
\frac{1}{2} \leq \frac{v_{i}}{v_{i_{0}}} \leq 2
$$

which means that no input variable can be more than twice as significant as the other.

Table 2. shows the results of the efficiency of the evaluated wellness hotels after adjusting the weight of the input variables, including reducing the input variables (photos, videos and links) so that the individual inefficient wellness hotels are effective.

Looking at the results of the DEA method from the aspect of the marketing communication of wellness hotels on the Facebook social network, inefficient production units need to reassess their activities on the given social network, as they have insufficient input rates and outputs. Inefficient marketing 
practices in communication area with Facebook users have an impact on the inefficiency of accommodation services. This inefficiency may result in a decrease in total revenue and insufficient occupancy of hotel facilities. This is a problem that requires the optimization of an online marketing communication strategy.

Table 2: The results of the efficiency evaluation of wellness hotels after adjusting the weight of input variables, including the reduction of input variables

\begin{tabular}{|l|l|l|l|l|l|l|}
\hline \multicolumn{1}{|c|}{ Hotel } & Efficiency & "Fotography" & "Video" & "Links" \\
\hline H1 & Village Resort Hanuliak & 0.314 & 167.052 & 40.507 & 0.985 \\
\cline { 2 - 7 } & H2 & Hotel Dixon & 0.602 & 195.673 & 123.157 & 0.383 \\
\hline H3 & Hotel Partizán & 0.764 & 408.399 & 91.775 & 1.168 \\
\hline H4 & Hotel Thermalpark & 0.514 & 410.231 & 148.565 & 0.000 \\
\hline H5 & Hotel Thermal & 0.322 & 215.828 & 99.860 & 0.322 \\
\hline H6 & Hotel Sorea Máj & 0.597 & 246.307 & 155.021 & 0.482 \\
\hline H7 & Hotel Rozsutec & $\mathbf{1 . 0 0 0}$ & $\mathbf{9 8 0 . 0 0 0}$ & $\mathbf{1 2 1 . 0 0 0}$ & $\mathbf{3 . 0 0 0}$ \\
\hline H8 & Hotel Holiday Park Orava & $\mathbf{1 . 0 0 0}$ & $\mathbf{7 8 4 . 0 0 0}$ & $\mathbf{9 8 . 0 0 0}$ & $\mathbf{0 . 0 0 0}$ \\
\hline H9 & Hotel Fugerov Dvor & $\mathbf{1 . 0 0 0}$ & $\mathbf{4 5 1 . 0 0 0}$ & $\mathbf{7 6 . 0 0 0}$ & $\mathbf{3 . 0 0 0}$ \\
\hline H10 & Garden Hotel \& Resort Oravský Háj & 0.660 & 491.702 & 203.949 & 1.980 \\
\hline H11 & Hotel Jullianin Dvor & 0.672 & 351.459 & 192.860 & 0.750 \\
\hline H12 & Grand Hotel Bellevue & 0.952 & 677.236 & 160.963 & 1.904 \\
\hline H13 & Grand Hotel Permon & 0.9113 & 586.112 & 345.465 & 1.387 \\
\hline H14 & Hotel Zochova chata & $\mathbf{1 . 0 0 0}$ & $\mathbf{5 1 0 . 0 0 0}$ & $\mathbf{3 2 1 . 0 0 0}$ & $\mathbf{1 . 0 0 0}$ \\
\hline H15 & Hotel Patince & $\mathbf{1 . 0 0 0}$ & $\mathbf{3 6 4 . 0 0 0}$ & $\mathbf{2 4 7 . 0 0 0}$ & $\mathbf{0 . 0 0 0}$ \\
\hline H16 & Hotel \& Spa Resort Kaskady & 0.978 & 574.175 & 225.953 & 2.144 \\
\hline Source: Authors & & & & \\
\hline
\end{tabular}

The main findings of the DEA analysis conducted by the researchers concluded that the main source of inefficiency in the funpages of the analyzed wellness hotels on Facebook is their respective input / output configuration, respectively the size of a hotel facility. This finding is also confirmed by the Association of Hotels and Restaurants of the Slovak Republic (2018), according to which there is an excessive offer of tourist accommodation facilities in Slovakia. Based on this, the wellness facilities of the hotel facilities should re-evaluate the accommodation capacity and use it more efficiently through the marketing communication on the Facebook social network in an attractive and interesting way leading to better use of the entertainment, leisure or other services rooms. This could be effective through pricing strategies.

\section{Discussion}

The research in this contribution concerned the assessment of the "funpage" effectiveness on the Facebook social network of selected wellness hotels operating in the Slovak Republic. Researchers have focused on data with the number of photos, videos, links, likes and comments that have been published and shared from 16 Slovak wellness hotels. From Table 2 above, which shows the effectiveness of these hotels through CCR DEA and Assurance Region models, including the input variable values. These models are input oriented, as the researchers' goal was to find out how Facebook was a tool of marketing communication and to choose a wellness hotel in Slovakia and not the other way around. Based on the above, Table 2 shows 5 effective wellness hotels as their efficiency score is 1 (H7, H8, H9, H14 and H15). Other rated wellness hotels have an efficiency score of less than one, which means they are not on an effective border. However, through the results of Table 2, it is also possible to identify sources of inefficiency, resp. how inefficient hotels should reduce their input variables around the number of photos, videos, and links being added to start working efficiently from the aspect of using their funpage on Facebook. For example, the Village Resort Hanuliak's efficiency exceeds 30\% (0.314). To make the hotel's funpage work efficient, it must reduce the addition of photographs to 167,40 videos, and less than 1 links while keeping its input variables. In this way, any inefficient wellness hotel could be continued. According to Table 1, which shows the input information, it is clear that the more wellness hotels publish their social media posts in the form of photos, videos, or links to promote their brands, thereby giving them more feedback. However, the results in Table 2 show that this is not the rule, as Sainaghi (2009) states, people who are too saturated with advertising can become immune to it. 
With this information and DEA methodology, it is possible to create entry and exit targets for wellness hotels in the Slovak Republic in a certain time frame. And this is based on the results of Table 2, which help the wellness hotel to determine what type of media (contribution in the form of photos, videos or links) is more suitable to increase the attractiveness of the wellness hotel category. Cao \& Yang (2011) reported that not quantity but quality content has resulted in an increase in the number of Likes and Comments, as the quality of the content of the article forces users to spread it further, respectively about him in his community. In addition to this, Morey \& Dittman (1995) considers the DEA method to be advantageous as it allows to indicate areas in which the promotion of hotel brands through the Facebook social network needs to be improved. In general, Facebook is a very effective marketing communication tool that wellness hotels use to promote their brands, as there is a place where a large number of potential hotel guests of different ages and sex are staying.

\section{Conclusion}

The present contribution represents the DEA (Data Envelopment Analysis) methodology, which evaluates the effectiveness of using the funpages of selected Slovak wellness hotels on the Facebook social network to support the brand of these hotels. The contribution focused on the commitment of hotel guests to the last funpage of wellness hotels on Facebook, which was also the main goal of the contribution. The contribution also shows that wellness hotels in the Slovak Republic use social networks, especially Facebook to engage and interact to promote the hotel brand with other users of social networks. The number of likes and comments is a sign that people are using the Facebook social network to learn more about the services offered by Slovak wellness hotels.

The proposed DEA methodology, resp. the DEA analysis models used (CCR model and Assurance Region) assume that smaller numbers of input variables (photos, videos, and links) on Facebook's social network are more appropriate, not only when the content of the posts is negative for the user. In addition, the models also do not assess the quality characteristics of added contributions, which can have a significant impact on the way users (fans) respond to posts.

In addition to the above, the authors believe that the DEA effectiveness assessment can be extended to other social networks, eg. Instagram, Twitter or YouTube, as the DEA method is a powerful tool for assessing efficiency by not requiring specification of formal relationships between inputs and outputs. Future research also suggests exploring multiple variables in order to evaluate the Facebook funpage effectiveness.

Despite the benefits provided by the DEA methodology, researchers are proposing to assess the effectiveness of the funpage wellness hotels in question on the Facebook social network through the Malmquist index, which, unlike the DEA analysis, accepts a time factor. In addition to the above, the subject of future research may be to extend this method to other categories of hotels with the possibility of their mutual comparison.

\section{Acnowledgement}

The contribution is the output of the project APVV-15-0505: Integrated Model of Management Support for Building and Managing the Brand Value in the Specific Conditions of the Slovak Republic.

\section{References}

Baker, M., \& Riley, M. (1994). New perspectives on productivity in hotels: some advances and new directions. International Journal of Hospitality Management, 13(4), 297-311.

Banker, R. D., Charnes, A., \& Cooper, W. W. (1984). Some models for estimating technical and scale inefficiences in data envelopment analysis. Management Science, 30, 1078-1092.

Barba-Gutiérrez, Y., Adenso-Díaz, B., \& Lozano, S. (2009). Eco-efficiency of electric and electronic appliances: a data envelopment analysis (DEA). Environmental Modeling \& Assessment, 14(4), 439-447.

Bartosova, V., \& Kral, P. (2016). A Methodological Framework of Financial Analysis Results Objectification in the Slovak Republic. European Proceedings of Social and Behavioural Sciences, 189-197. Mara, Malaysia: Future Acad-Cyprus.

Bell, R. A., \& More, R. C. (1995). Incresing the efficiency o corporate travel management throught macro benchmarking. Journal of Travel Research, 33(3), 11-20.

Boyd, D. M., \& Ellison, N. B. (2007). Social network sites: definition, history and scholarship. Journal of Computermediated Communication, 13(1), 210-230.

Cao, X., \& Yang, F. (2011). Measuring the performance of Internet companies using a two-stage data envelopment analysis model. Enterprise Information Systems, 5, 207-217.

Coelli, T. J. (1995). Recent developments in frontier modelling and efficiency measurement. Australian Journal 
of Agricultural and Resource Economics, 39(3), 219-245.

Faranda, M., \& Roberts, L. D. (2019). Social comparisons on Facebook and offline: the relationship to depresive symptoms. Personality and Individual Differences, 141, 13-17. doi: 10.1016/j.paid.2018.12.012.

Charnes, A., Cooper, W. W., \& Rhodes, E. (1978). Measuring the efficiency of decision-making units. European Journal of Operational Research, 2, 429-444.

Internet World Stats. (2018). Retrieved form https://www.internetworldstats.com/stats4.htm

Jablonsky, J., \& Dlouhy, M. (2015). Modely hodnoceni efektivnosti a alokace zdroju. Praha: Proffesional publishing.

Jakovic, B., \& Galetic, F. (2014). Marketing and commercial activities offered on Croatian five-star hotel websites.

Engineering, 69, 112-120.

Johns, N., Howcroft, B., \& Drake, L. (1997). The use of data envelopment analysis to monitor hotel productivity. Progress in Tourism and Hospitlity Research, 3(2), 305-360.

Kang, J. (2018). Effective marketing outcomes of hotel Facebook pages the role o active participation and satisfaction. Journal of Hospitality and Tourism Insights, 2(1), 106-120. doi: 10.1108/JHTI-10-2017-0003.

Kliestik, T. (2009). Kvantiikacia eektivity cinnosti dopravnych podnikov pomocou Data Envelopment Analysis. $E+M$ Ekonomie a manažment, 1, 133-145.

Kliestikova, J., \& Janoskova, K. (2017). Branding with understanding: how national profile of consumer influences brand value perception. Marketing and Management of Innovations, (3), 149-157.

Kolarova, I., Bediova, M., \& Rasticova, M. (2017). Job opportunities for people over 50 in the Netherlands. Forum Scientiae Oeconomica, 5(1), 119-128.

Lothia, R., Donthu, N., \& Yaveroglu, I. (2007). Evaluating the efficiency of Internet banner advertisements. Journal of Business Research, 60(4), 365-370.

Meila, A. D. (2018). The social structure of cities: the multidimensional nature o urban inequality. Psychosociological Issues in Human Resource Managemet, 6(1), 115-120.

Ministry of Transport and Construction of the Slovak Republic. (2018). Retrieved from https://www.mindop.sk/ministerstvo1/cestovny-ruch-7/statistika/domaci-cestovny-ruch

Morey, R. C., \& Dittman, D. A. (1995). Evaluating a hotel GM'S performance: a case study in benchmarking. The Cornel Hotel and Restaurant Administration Quarterly, 36(5), 30-35.

Nadanyiova, M. (2017). Neuromarketing - an opportunity or a threat? Communication: scientific letters of the University of Zilina, 19(4), 90-94.

Neves, J., \& Lourenco, S. (2009). Using data envelopment analysis to select strategies that improve the performance of hotel companies. International Journal of Contemporary Hospitality Management, 21, 698-712.

Okuneviciute, N. L., \& Pranskeviciute, I. (2018). Overcoming paradox for social enterprise deinition: case of Lithuania. Ekonomicko-manazerske spektrum, 12(1), 104-118.

Olah, J., Zeman, Z., Balogh, I., \& Popp, J. (2018). Future challenges and areas of development for supply chain management. Logforum, 14(1), 127-138.

Pham, G. V., Shancer, M., \& Nelson, M. R. (2019). Only other people post food photos on Facebook: third-person perception of social media behavior and effects. Computer in Human Behavior, 93, 129-140. doi: 10.1016/j.chb.2018.11.026.

Sainaghi, R. (2010) Hotel performance: state of the art. International Journal of Contemporary Hospitality Management, 22, pp. 920-952.

Salaga, J., Bartosova, V., \& Kicova, E. (2015). Economic Value Added as a measurement tool of financial performance. Procedia Economics and Finance, 26, 484-489.

Shuai, J., \& Wu, W. (2011). Evluating the influence of e-marketing on hotel performance by DEA and grey entropy. Expert Systmes with Applications, 38(7), 8763-8769.

Zväz hoteĺov a reštaurácii Slovenskej republiky. (2018). Retrieved from http://www.zhrsr.sk/index.php/aktuality/statistiky/606-statistika-podla-rokov\#.WoazGqjwaUk 